\title{
Emil v. Grósz †
}

Der emeritierte Vorstand der Budapester Univ.-Augenklinik N $\gamma$. 1, Hofrat Prof. Dr. Emil v. Grósz, ist am 8. Dezember 1941 im Alter von 76 Jahren an einem Herzschlag plötzlich gestorben. Die ungarische Ophthalmologie be-trauert in ihm ihren Altmeister, dem sie ungemein viel zu verdanken hat. Sein Name ist mit der Blütezeit der ungarischen Ophthalmologie aufs engste verbunden und auch im Auslande, wohl bekannt. E. v. Grósz entstammt einer Augenärztefamilie: sein Großvater Friedrich Grósz stiflete das erste Augen-spítal in der ungarischen Provinz im Jahre 1830, in Nagyvárad; der Vater, Albert Grósz, war auch ein bekannter Augenarzt.

E. v. Gyósz war Schüler und Nachfolger Schuleks an der Budapester Univ.-Augenklinik, die er 32 Jahre lang als Direktor leitete. Seine Schule und die hervorragenden Leistungen seiner Klinik waren auch im Auslande gut bekannt. Sein Leben ist durch eine überaus große Arbeitslust und erstaun-liche Leistungsfäliigkeit gekennzeichnet, die sich nicht nur auf die Augen-heilkunde, sondern mit der gleichen Hingabe auf alle ärztlichen Fragen er-streckte. Der Verstorbene w $\tau$ ar nicht nur ein ausgezeichneter Kliniker, ein vorzüglicher Operateur und Lehrer, den bis zur letzten Stunde alle wissen-schaftlichen Fragen interessierten, sondern er befaßte sich nebenher auch sehr viel mit allgemeinen medizinischen und hygienischen Problemen, wobei er ganz

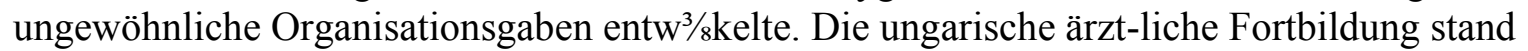
bald 30 Jahre unter seiner Führung. Als Vorkämpfer für die Errichtung von Augenabteilungeii und Augenspitälern in Ungarn hat sich v. Gүósz unvergängliche Verdienste erworben. Vor allem war er der Organisator und durch lange Jahre Regierungskommissär der Trachom-Bekämpfung in Ungarn, deren gesetzliche Regelung v. Gyósz zu verdanken ist und die zum Vorbild für viele ausländische Verordnungen geworden ist. Daher wurde auch er zum ersten Vorstand des Internalionalen Komitees für Bekämpfung des Trachoms in Amsterdam gewählt.

Die wissenschaftliche und augenärztliche Tätigkeit von v. Gyósz betraf in erster Reihe klinische, weniger theoretische Probleme. Seine Lieblings-themata waren: die sympathische Ophthalmie, die operative Behandlung des Glaukoms, das Trachom, die Sehnervenatrophie, das Sarkom der Chorio-idea. Sehr lehrreich waren stets die Berichte über die Tätigkeit seiner Klinik: die hohen Zahlen der Operationen sind nicht nur imponierend, sondern legen aucli Zeugnis ab von den erzielten schönen Erfolgen. Unabsehbar ist die Zahl ausländischer Augenärzte, die seiner gastfreundlichen Einladung Folge lei-steten und ihn und seine schöne Klinik bei der Arbeit kennen gelernt haben.

176 Book-Notices - Buchbesprechungen - Livres Nouveaux

An der Gründung de $\Gamma$ Ung. Ophthalmologischen Gesellschaft hat v. Grósz tatkräftig mitgewirkt und war jahrelang ihr Präsident und später Ehren-mitglied. Seine Teilnahme an ausländischen Kongressen und die von ihm angeknüpften persönlichen Beziehungen zu ausländischen Kollegen warben viele aufrichtige Freunde für die ungarischen Augenärzte. Es gab kaum eine Tagung der deutschen, französischen oder englischen Ophthalmologischen Gesellschaften oder einen Internationalen Ophthalmologen-Kongreß, an dem der Verstorbene nicht teilgenommen hätte. 
Die Schule, die er gegГÜndet hat, lebt weiter in seinen zahlreichen Schülern, die ihren unvergeßlichen Lehre $\Gamma$ tief betrauern und seiner stets in treuer Dankbarkeit und Verehrung gedenken werden. G. Hozay, Budapest.

Buchbesprechungen - Books Review - Livres Nouveaux

Q. Di Marzio: Fundus oculi, Ophthalmoskopische Diagnose. Verlag Bosen-berg \& Sellier, Turin. Lire 800.-.

D. Der glänzend ausgestattete ophthalmoskopische Atlas bringt auf 100 Ta-feln 212 farbige Abbildungen des Augenhintergrundes, die nicht $\pi$ ur diehäufigeren

Augenhintergrundserk ankungen betreffen, sondern auch seltenereAffektionen, wie die angioide Streifenbildung, die Angiomatosis retinae, dieFundusveränderungen bei der amaurotischen Idiotie, der Meningitis serosaund der Arachnoiditis optico-chiasmatica. Die Abbildungen, die von derMalerin Fräulein A. Maggioli angefertigt worden sind, stellen sich würdigneben den großen OeZZerschen Atlas, nur daß hier auch manche Erkrankun-gen gebracht werden, die zu $\gamma$ Zeit der Anfertigung des genannten Atlas vorüber vierzig Jahren noch nicht bekannt waren. So ist das Werk, das, wieVerfasser in der Vorre.de sagt, für junge Augenärzte und Studenten gedachtist, auch für die älteren Fachkollegen äußerst instruktiv. Das gilt um so mehr, als kurze Krankengeschichten, bei denen immer auch der Allgemeinbefundin moderner Weise Berücksichtigung findet, den Abbildungen beigegebensind. Besondere Aufmerksamkeit fand die Netzhautabhebung, bei der sehranschaulich die Bilder vor und nach der erfolgreichen Operation gegeben werden. Die Uebersetzung des Textes aus dem Italienischen ist durch E. B. Stieiff, Genf, vorgenommen worden, eine englische, die von Girolamo Bonaccoltobesorgt worden ist, ist dem Werke beigefügt. Dem berühmten Fachkollegender Universität Bologna können wir zu diesem Mussolini gewidmeten Werkeallerbeste Glückwünsche aussprechen. Es ist nach Inhalt wie nach Ausstat-lung vortrefflich. Bruckner, 